\title{
Quand les enfants parlaient de gloire. L'armée au cœur de la France de Napoléon
}

\section{Annie Crépin}

\section{(2) OpenEdition \\ Journals}

Édition électronique

URL : https://journals.openedition.org/ahrf/9553

DOI : $10.4000 /$ ahrf.9553

ISSN : 1952-403X

\section{Éditeur :}

Armand Colin, Société des études robespierristes

\section{Édition imprimée}

Date de publication : 1 juin 2007

Pagination : 212-214

ISSN : 0003-4436

\section{Référence électronique}

Annie Crépin, «Quand les enfants parlaient de gloire. L'armée au cœur de la France de Napoléon », Annales historiques de la Révolution française [En ligne], 348 | Avril-Juin 2007, mis en ligne le 23 juillet 2008, consulté le 30 avril 2022. URL : http://journals.openedition.org/ahrf/9553 ; DOI : https://doi.org/ 10.4000/ahrf.9553

Ce document a été généré automatiquement le 30 avril 2022.

Tous droits réservés 


\title{
Quand les enfants parlaient de gloire. L'armée au cœur de la France de Napoléon
}

\author{
Annie Crépin
}

\section{RÉFÉRENCE}

Jean-Paul Bertaud, Quand les enfants parlaient de gloire. L'armée au cœur de la France de Napoléon, Paris, Aubier, coll. historique, 2006, 460 p., ISBN 978-2-7007-2348-9, $25 €$.

1 Dans la lignée de son ouvrage Guerre et société en France de Louis XIV à Napoléon, mais en focalisant son analyse sur la nation et la société consulaire et impériale, J.-P. Bertaud se livre ici à une histoire des mentalités et des sensibilités, brillante synthèse de ses travaux actuels sur les concepts d'honneur et de gloire. Le propos de l'auteur est de montrer la militarisation des consciences, des cœurs et des imaginations mais aussi ses limites et les oppositions qu'elle rencontra.

2 Neuf chapitres structurent l'ouvrage. Le premier est consacré à un rappel du contexte dans lequel s'inscrit l'étude, un contexte marqué par l'héritage de la Révolution et les nouveaux rapports qu'elle a établis entre l'armée et la nation devenue la Grande Nation sur fond de guerre permanente. À propos de la confrontation entre la France et les monarchies européennes, J.-P. Bertaud rappelle avec beaucoup de pertinence que «l'Empereur de guerre » n'est pas le "Jacobin botté » en dépit de ce qu'il prétendit pour justifier une politique extérieure conquérante. Napoléon Bonaparte n'est pas pour autant l'unique responsable de la guerre prolongée même si elle est le fondement de ses projets et de ses actes. En même temps, et l'auteur réitère ce qu'il a dit dans ses précédents travaux, le despotisme impérial n'est pas dictature militaire, «l'Empereur de guerre » ne souhaite pas gouverner par et pour l'armée.

La place de celle-ci dans la société nouvelle est analysée dans les pages quasi balzaciennes du second chapitre dont l'objet est l'origine, la formation, la fortune et les 
revenus des officiers, la promotion sociale que la guerre leur vaut éventuellement. Si l'histoire culturelle est essentielle dans ce livre, l'histoire sociale n'est pas dédaignée en effet. Une différenciation très nette est opérée entre officiers subalternes et officiers supérieurs. Au sujet de ceux-ci, on pourrait presque parler d'envers de l'épopée quand on prend connaissance des "comptes fantastiques des maréchaux ou des généraux " (p. 83). L'auteur rappelle cependant que ceux qui avaient accédé aux échelons les plus hauts ne firent pas tous de la guerre une entreprise et qu'à l'inverse les officiers subalternes " plus riches de gloire que d'argent » (p. 57) se livrèrent au pillage ou à des malversations. Ces officiers deviennent des notables et même des nobles, la noblesse impériale se recrutant essentiellement parmi eux. Retraités, ils occupent des emplois dans l'administration et l'appareil d'État de l'ancienne France, encore en activité, des postes dans ceux des pays annexés ou vassaux. Cela ne veut nullement dire que l'empereur ait voulu réserver un rôle spécial à l'armée ou une situation privilégiée à ses officiers, mais qu'il se préoccupe de leur retour à la vie civile.

4 Le problème est que ces personnages se considèrent toujours comme supérieurs et «à part ». Le troisième chapitre contient des pages savoureuses sur la petite guerre que les officiers livrent aux civils, notamment aux préfets, pour les honneurs et les préséances dans les cérémonies publiques, y compris pendant les Cent-Jours. Il n'y a pas là qu'anecdotes et J.-P. Bertaud montre que les épisodes de cette "guéguerre » au cours de laquelle Napoléon ne tranche pas vraiment sont révélateurs de la forte coloration militaire du régime et des limites de l'entente des notables que l'empereur désirait cependant. Dans une certaine mesure, ils remettent en question sur le plan symbolique le principe de la suprématie du pouvoir civil hérité de la Révolution.

5 Le quatrième chapitre se place au niveau des petits et des sans-grade. C'est de nouveau l'envers de l'épopée qui est évoqué dans des pages fortes et sobres concernant la vie des soldats. Ceux-ci sont recrutés par la conscription qui entraîne une militarisation de la jeunesse masculine sans égale jusque là, du moins jusqu'en 1789. Conscription désormais subie comme impôt du sang plus qu'acceptée comme devoir du citoyen, étant donné les détournements de la loi Jourdan opérés par Napoléon et les inégalités profondes qui en sont la conséquence. Même avant les retours massifs de 1815, le sort réservé aux anciens soldats n'est pas meilleur, leur réinsertion dans la société civile n'est pas facilitée par le régime en dépit de sa propagande. La politique sociale envers les vétérans reflète les inégalités que l'on a déjà vues à l'œuvre au sein même du corps de officiers, encore plus à l'égard des veuves et des orphelins qu'ils laissent.

6 Les chapitres suivants qui sont le cœur de l'ouvrage déclinent dans plusieurs domaines la militarisation des esprits, des consciences et des cœurs que veut entreprendre Napoléon Bonaparte dès son accession au pouvoir. Les moyens de ce qui n'est pas simple propagande mais se veut conquête intellectuelle, spirituelle et affective sont étudiés avec acuité. Le cinquième chapitre analyse le sens nouveau que revêt le terme d'honneur. L'éthique militaire que Napoléon veut inculquer aux élites et dont il tend à imprégner les nouvelles institutions aurait peut-être dû être davantage distinguée de la culture de guerre et même du bellicisme. Les Français ont pu se monter rétifs à celle-là s'ils étaient spontanément de connivence avec ceux-ci. Une chose est de se glorifier des victoires, une autre est d'accepter d'y participer personnellement, encore une autre de se plier à la discipline des camps transposée dans la vie civile comme le prouvent, de l'aveu même de l'historien, les réticences des notables à placer leurs fils dans les lycées. 
7 Cette éthique militaire doit autant à la vertu civique de la cité nouvelle qu'à l'honneur traditionnel ou plutôt, dans ce vocable d'honneur, se mêlent les emprunts que Napoléon Bonaparte fait à la fois à la noblesse, à l'armée, à la Révolution. Dans des pages pénétrantes, l'auteur montre qu'il ne peut plus être désormais gloriole ni même gloire personnelle, il doit être volonté d'œuvrer pour le bien commun; la société de l'honneur est censée accélérer la fusion des anciennes et nouvelles élites chez les notables. La tâche d'incarner l'honneur ne revient donc pas exclusivement aux militaires comme le prouve l'institution de la Légion d'honneur qui s'adresse aussi à des civils, selon la volonté explicite du premier Consul.

8 Avec cette militarisation des institutions, on se trouve dans le long terme, après tout Napoléon s'adressait autant aux fils des notables qu'à leurs pères. Dans les sixième, septième et huitième chapitres, on est davantage dans le court terme et plus près de la culture de guerre. D'abord, grâce au système concordataire, l'empereur enrôle les religions et leurs prêtres à son service pour justifier la guerre et faire croire à leurs fidèles qu'elle est défensive. Évêques, pasteurs et rabbins s'emploient à élaborer une théologie de la guerre juste et à trouver dans la Bible des arguments qui sacralisent la conquête et celui qui la mène.

9 Mais c'est aussi l'imaginaire public que Napoléon s'efforce de toucher par le biais des fêtes, la mise en scène de la lecture des bulletins de la Grande Armée et la mise en scène, au sens propre du terme, des pièces de théâtre et des opéras. Parades et défilés concourent au culte de la gloire. Théâtre, devenu département du ministère de la Gloire selon une heureuse formule de J.-P. Bertaud, et culture populaire sous la forme de chansons et de romans - dont on apprécie que l'auteur analyse le répertoire beaucoup moins spontané qu'il n'y parait - sont les vecteurs de ce culte qui se propage aussi grâce à son esthétisation. Celle-ci est le fait des arts plastiques et de l'architecture. Si les architectes n'ont pu réaliser leurs projets, les œuvres des peintres montrent qu'ils se sont faits les artistes de la victoire et les instruments du ministère de la Gloire.

10 Le dernier chapitre est consacré à la contre culture de la gloire, en fait le refus opposé aux tentatives de militarisation, encore plus à la culture de guerre. C'est d'abord le refus de faire celle-ci par l'insoumission. Toutefois, on aurait souhaité que l'historien montre davantage l'extraordinaire diversité des attitudes des Français devant la conscription napoléonienne. La bonne conscience des notables faisant l'éloge du bienfondé de la conscription alors qu'ils y échappent n'est pas qu'hypocrisie, fustigée par J.P. Bertaud. Il y eut des départements, des régions, pour être en accord avec ces vues. Les résistances au bellicisme se fortifient à la fin du régime et il y a une analyse très pertinente des attitudes des Français devant les militaires vaincus en 1814 ainsi que du décalage social et culturel entre les premiers qui aspirent à la paix et les seconds qui veulent continuer le combat. Les difficultés de la réinsertion des vétérans ne viennent donc pas que de la politique de la Restauration. Ce qui donne à penser que les vecteurs de la culture de guerre n'avaient pénétré que superficiellement la société civile. Quant à l'imprégnation de l'éthique militaire, il lui a manqué du temps et elle se heurtait elle aussi, comme le dit l'auteur en conclusion, à un vieille méfiance des Français devant le fait militaire et ceux qui l'incarnaient tout en pouvant se combiner parfaitement - et temporairement - à leur élan guerrier, comme nous espérons l'avoir montré dans nos propres travaux. 